Relations industrielles

Industrial Relations

\title{
La médecine du travail, médecine humaine, par Dr Pierre Delaunay, Éditions du Centurion, Paris, 1968, 138 pages.
}

\section{Pierre Dionne}

Volume 23, numéro 4, 1968

URI : https://id.erudit.org/iderudit/027968ar

DOI : https://doi.org/10.7202/027968ar

Aller au sommaire du numéro

Éditeur(s)

Département des relations industrielles de l'Université Laval

ISSN

0034-379X (imprimé)

1703-8138 (numérique)

Découvrir la revue

Citer ce compte rendu

Dionne, P. (1968). Compte rendu de [La médecine du travail, médecine humaine, par Dr Pierre Delaunay, Éditions du Centurion, Paris, 1968, 138 pages.]

Relations industrielles / Industrial Relations, 23(4), 703-703.

https://doi.org/10.7202/027968ar

Tous droits réservés (C) Département des relations industrielles de l'Université Laval, 1968
Ce document est protégé par la loi sur le droit d'auteur. L’utilisation des services d'Érudit (y compris la reproduction) est assujettie à sa politique d'utilisation que vous pouvez consulter en ligne.

https://apropos.erudit.org/fr/usagers/politique-dutilisation/ 
La médecine du travail, médecine humaine, par Dr Pierre Delaunay, Editions du Centurion, Paris, 1968, 138 pages.

On imagine mal ce que serait la vie des entreprises et des travailleurs sans le médecin du travail. Cependant, on voit tout aussi mal son véritable rôle, sa présence propre dans la lutte pour la santé des groupes humains et des personnes tels que la production les réunit. Comme souvent, nous sommes sans expérience véritable de ce qui nous est devenu indispensable, la médecine du travail n'a donc aucunement besoin d'être justifiée, mais il faut l'identifier. C'est à quoi s'attache le docteur Pierre Delaunay sans qu'il ne soit question ni de défense, $\mathrm{ni}$ d'illustration.

Après une brève historique de la médecine du trovail, l'auteur traite de son évolution et de son organisation. La formation et le rôle du médecin font l'objet du troisième chapitre. L'organisation, le fonctionnement, les incidences sur les individus d'un service médical dans l'industrie sont autant de sujets envisagés par la suite dans cet ouvrage. Enfin, l'outeur termine son étude en regardant successivement les relations entre la médecine du travail et les cadres, les représentants du personnel, le service social d'entreprise et le coût de la médecine du travail.

Ce petit ouvrage, très schémotique, peut très bien servir de guide pour des lectures plus poussées sur ce sujet. II s'adresse particulièrement à tous ceux qui s'intéressent de près ou de loin au monde du travail.

\section{Pierre DIONNE}

Creating a Market, International Labour Office, Genève, 1968, 127 pages.

Voici un autre livre d'enseignement programmé que nous présente l'ILO. Qu'est-ce que l'enseignement programmé? Tel que mené dans cet ouvrage, l'enseignement progrommé est une véritable leçon que l'élève apprend en utilisant un questionnaire. Le questionnaire est construit de telle sorte que l'étudiant commençant à répondre aux questions les plus simples est amené à répondre à des questions de plus en plus difficiles. L'étudiant peut vérifier la justesse de ses réponses en se corrigeant lui-même grâce oux réponses fournies par l'ouvrage, grâce oussi à une bibliographie donnée en onnexe.

L'enseignement donné par cet ouvrage-ci concerne les marchés, la mise en marché des produits, la différenciation des produits. Pourquoi un enseignement sur les marchés par I'ILO? On sait que I'ILO se préoccupe surtout de répandre dans les sociétés industrielles ou en voie d'industrialisation des techniques directoriales, des méthodes pour développer la productivité; mais, comme le disent les auteurs, les fonctions directoriales sont toutes interdépendantes dans l'industrie et à quoi servirait de développer à l'extrême les théories et méthodes de management si les autres fonctions restent anémiques et mettent ainsi en danger la survie même des organisations. Dans cette optique, le développement des techniques de création des marchés et de mise en marché est une des préoccupations majeures de l'économie contemporaine et des sociétés industrielles.

Le présent cours sur la création des marchés comporte les étapes suivantes:

1-Le dégagement des concepts fait un bref rappel des techniques et des stratégies de marketing permettant ainsi à l'étudiant d'acquérir d'abord le vocabulaire courant dans le domaine, ensuite la préoccupation globale de cette activité.

2-La recherche du marché concerne expressément les champs possibles pour ouvrir ou pour étendre un marché. La recherche s'attarde d'abord à l'étude du marché actuel, puis à l'étude des possibilités offertes, soit du côté des consommateurs, soit du côté des nouveaux produits.

3- La planification des produits par la sélection, la modification, la différenciation des produits offerts sur le marché.

4-La fixation des prix, déterminée par les coûts de production et de mise en marché et par la demande solvable, ne peut faire abstraction des études concernant la compétition, l'augmentation de la demande solvable et la réduction des coûts à court et à long terme.

5-La publicité, la promotion des ventes et la distribution des produits.

Enfin, signalons que l'ouvrage fournit une excellente bibliographie, un lexique des termes couramment utilisés en marketing, d'excellentes sources d'information statistique soit pour l'économique en général, soit spécifiquement pour le marketing. 